\title{
Decreased Device Sensitivity
}

National Cancer Institute

\section{Source}

National Cancer Institute. Decreased Device Sensitivity. NCI Thesaurus. Code C63253.

Problem with a medical device being less sensitive to an input than intended or expected. 